\title{
Entrevista com Paul Willis
}

Por Melissa Mattos Pimenta

Tradução de Melissa Mattos Pimenta

A leitura da entrevista realizada em 1998 por Roger Martínez despertou nosso interesse com relação ao trabalho posterior de Paul Willis e à sua visão atual sobre os temas então abordados, com destaque para a questão da juventude. A idéia de "atualizar" a entrevista "Culturas vivas" deveu-se tanto à temática específica desse número da revista Tempo Social, para a qual a contribuição do autor é importante, quanto à própria curiosidade científica que suas proposiçôes despertam nos leitores brasileiros familiarizados com seu trabalho. As questões colocadas a seguir são fruto de nosso contato on-line com Paul Willis, que muito cordialmente aceitou colaborar com o projeto de desenvolvimento e atualização do texto publicado originalmente na revista Estudios de Juventud.

Na entrevista de 1998, o senhor afirmou que vinha procurando afastar-se do determinismo estrutural, sem, contudo, abdicar do contexto estrutural. O senhor propôs integrar na mesma obra a cultura, a experiência, a identidade e a posição estrutural. Como pesquisador, de que maneiras o senhor propóe dar conta de todas essas dimensöes?

Eu quero ser implacável na busca pela internalidade das relações possíveis e dos laços que se sobrepõem conectando indivíduos e estruturas mais amplas. A cultura cotidiana é o principal meio-termo que quero acrescen- 
tar como mediação entre indivíduos e estruturas. Vejo as produções desse campo simbólico (cultura, ou culturas dentro das diferentes esferas) como resultado, em parte, mediante condiçôes, da atividade própria, criativa, autônoma e etnograficamente registrável dos agentes que, por meio dela, produzem e reproduzem a si mesmos. Mas o campo simbólico também opera em um outro nível, no qual se encontra visceralmente envolvido, na manutenção e na formação diferenciada do todo social ou de toda formação social, incluindo a reprodução das condiçôes pelas quais, originalmente, ocorre a "atividade própria" (dos indivíduos).

Essa reprodução social não ocorre, porém, mecanicamente, como se por meio de uma física social, mas por meio de uma complexidade sociosimbólica que envolve, entre outras coisas, ironias e conseqüências não intencionadas. Meu argumento é de que há uma pungência na qual a situação social/estrutural é articulada, não como uma determinação externa, tampouco como um "apêndice" descritivo do contexto, mas como uma relação interna e uma qualidade da "produção humana de sentido". Por meio das mediações simbólicas de suas culturas coletivas, os agentes sociais gozam da habilidade de "perceber" ou "penetrar em" aspectos da estrutura ou do processo social como algo a ser compreendido, ou que provê campos de coisas a serem descobertas ou entendidas, ou, ainda, que carrega seus próprios sentidos possíveis, incluindo posiçôes ideológicas, que podem ser adotadas, contestadas, explicadas ou recusadas. E é por meio da operação desses processos culturais que, por fim, contraditoriamente e sempre com um duplo viés, as estruturas dominantes ou suas condiçóes de possibilidade são reproduzidas.

O senhor também afirmou que a era das subculturas espetaculares chegou ao fim, e que não há mais culturas autênticas. Como devemos entender a apropriação do simbólico pela sociedade de consumo? O que resta aos etnógrafos para descobrir?

Desde 1960, Asa Briggs definiu a mudança crucial produzida pela industrialização e pela comercialização do campo simbólico: "Poderosos interesses de mercado vêm cada vez mais dominando uma área da vida que até recentemente era dominada pelos próprios indivíduos”. Esse campo cultural que tanto me interessa hoje é totalmente dominado pela produção de artigos de consumo visando ao lucro, o que traz consigo a resultante conversão, em bens consumíveis, dos materiais culturais, das 
relações e dos serviços que são as pás que movem o moinho da vida cotidiana. A "atividade criativa própria" dos agentes vai de encontro a essa nova dominação daquilo que antes lhes era "próprio", e esse encontro colore todo o campo cultural, que, por sua vez, está implicado nos processos contemporâneos de reprodução social diferenciada (mantendo a estabilidade ou levando ao conflito social). Mas o papel da "atividade criativa própria” dos agentes, etnograficamente registrável, é crucial para o modo como essas mudanças tecnológicas e político-econômicas se efetivam ou são compreendidas como mudança cultural e social. Meu recente livro, The Ethnographic imagination, atualiza a visão marxista do papel dos bens culturais na formação da cultura moderna, argumentando que, contraditoriamente, o fetichismo consumista renovado estreita, distorce e ao mesmo tempo, de modo curioso, possibilita as produções culturais simbólicas informais dos jovens.

Atualmente, como o sentido é produzido?

A vida cotidiana implica uma produção humana, habitual, de sentido. Os seres humanos são levados não apenas à luta pela sobrevivência por meio da produção e da reprodução das condições materiais de existência, mas também por intermédio da compreensão do mundo e de seu lugar nele. Em outras palavras, do entendimento de si mesmos em seu próprio mundo cultural. Os atos culturais são intrinsecamente motivados como aspectos da construção da identidade. Essa identidade deve ser viável e acreditável, no sentido de saber "como continuar em frente" no mundo social e também no sentido de ganhar aceitação e respeito dos outros, mesmo na luta material pela existência, buscando e encontrando dignidade e reconhecimento e, mais ainda, descobrindo significado e sentido cultural para além dos papéis sociais específicos do "mundo informal da vida". Talvez o equilíbrio entre a luta instrumental e a luta expressiva tenha se modificado de tal modo que, hoje, os humanos estejam mais empenhados na produção de seu mundo cultural do que de seu mundo material. A produção do sentido de si e de seu mundo cultural é alcançada, de modo crucial, pelas práticas culturais que produzem algo que ainda não estava lá, ao menos não completamente ou da mesma maneira.

Uma das tendências mais importantes na sociologia contemporânea é a teoria e o debate sobre a individualização. Como pesquisador voltado para os estudos 
1. Ou Teddy boys, outra tribo de jovens inglesa surgida na década de 1950, caracterizada por vestir-se com paletós longos e largos com colarinhos de veludo e calças justas (N. T.). culturais, de que maneira o senhor vê a produção cultural em um mundo cada vez mais individualizado?

Os "velhos" mundos culturais não fornecem mais práticas e materiais acreditáveis. Tradiçōes de classe, trabalho, sindicatos, a Igreja, a família, os parentes, a educação humanista liberal - essas coisas não mais situam e preenchem a identidade de maneiras conexas e homogêneas. Ninguém sabe mais quais são os mapas sociais, não há pertencimento automático, de modo que você deve lutar e construir seu próprio significado cultural, participando da produção e da reprodução de si próprio. Evidentemente, isso não significa que as práticas culturais se dêem no vazio ou detenham apenas um conteúdo "racional". Sem tradições conscientes próprias, os escombros remanescentes de outrora sobrevivem e sofrem mutações, encontrando novas áreas de relevância parcial. Há ainda tradiçôes informais relacionadas ao gênero, ao humor e à apresentação social, por exemplo, que continuam constituindo o material de construção dos edifícios formais decadentes e que ainda se encontram disponíveis para novas formas de construção. Há também uma importante dimensão contemporânea nos materiais disponíveis para a constituição do sentido. A produção de si, tomada como produção do mundo cultural, há muito é reconhecida como um fenômeno subcultural - eu sou (ao menos por algum tempo) um Ted ${ }^{1}$, um hippy, um mod, um skinhead -, mas hoje isso é muito mais parte da experiência cotidiana majoritária. Isso pode ser encontrado na participação restrita em estilos culturais "retrôs" (não mais "juvenis") ou em certas paixões como futebol, Elvis, country e western. Mas também em responsabilidades corriqueiras, como decidir de que modo "seguir em frente" quando "as coisas mudaram tanto", de que maneiras encontrar referências morais ou critérios para fazer escolhas quando a "tradição" não ajuda muito, mas (ao mesmo tempo) uma enorme variedade de pistas está disponível, em uma complexa e confusa rede de chats de amigos, TV, novelas, filmes, anúncios, programas de auditório, revistas, músicas deliberadamente colocadas para tocar ou ouvidas ao acaso no rádio, conversas com colegas de trabalho e de estudos.

Como cientistas sociais, podemos reconhecer os significados que os individuos produzem para suas práticas sociais em um contexto inundado pela produção em massa de bens de consumo? 
Os agentes sociais não são sociólogos acadêmicos nem obedecem a uma organização em grupos de seminários, de modo que suas práticas de produção de sentido requerem alguma investigação, um pouco de interpretação e, é claro, uma metodologia etnográfica. O "pensamento vivido" e "sensível", incorporado e enraizado, normalmente não é expresso na linguagem. Por vezes ele é, de fato, organizado contra a linguagem ou em conflito com ela. Isso pode ser percebido, quase inconscientemente, como uma forma de operação de um poder inaceitável, algo com o qual devemos lidar, que devemos evitar ou recusar em vez de tomar como um reflexo transparente dos interesses e das motivações pessoais de um indivíduo.

Depois, na entrevista, o senhor descreveu sua experiência na The Youth Review, na qual fala sobre "a nova condição social do desemprego". Com base em sua experiência com jovens trabalhadores, de que maneiras o desemprego afeta as transiçôes para a vida adulta nos dias de hoje?

O salário permite uma série de emancipaçōes culturais, além de dar acesso ao mundo do consumo. Ele traz um sentido de si mesmo e de maturidade que é conquistado por meio do discernimento e da experiência, mais do que pelo mero acúmulo de anos vividos, pela atribuição de alguém ou por uma certificação institucional. O desemprego juvenil conduz a transiçôes econômicas interrompidas, mas também a transiçôes culturais, sociais e políticas não concluídas. A expectativa de ter um salário tem sido negada a parcelas significativas da classe trabalhadora, e a ameaça de deixar de recebêlo tornou-se uma condição permanente para todos os trabalhadores. Para compreender totalmente o impacto disso é importante perceber que o salário não é simplesmente uma quantia em dinheiro. Certamente, é a única recompensa visível para o trabalho sob o capitalismo, e como tal provê o acesso aos bens culturais, aos serviços e às formas criativas das práticas culturais discutidas acima. Mas o salário também é o pivô crucial de vários outros processos e transiçôes sociais e culturais que pouco têm a ver com dinheiro. Mais importante que isso talvez seja o fato de que o salário ainda é a chave de ouro (financiamento, aluguel, contas) para um domicílio pessoal separado dos pais e separado do trabalho e da produção. A casa é a principal personificação da "liberdade e independência" do trabalhador em relação ao capital - além do trabalho assalariado, evidentemente, que é o preço pela independência de viver em uma residência própria. Mas esse preço realmente compra alguma coisa. O domicílio é uma área de privacidade, segu- 
rança e proteção em relação à agressividade e à exploração do trabalho, às dependências patriarcais da casa dos pais e às vicissitudes do mercado. A moradia separada ainda é o objetivo universal da classe trabalhadora e sua promessa de calor e segurança mais do que compensa os riscos e a frieza do trabalho. $\mathrm{O}$ trabalho assalariado é a chave para seu oposto. Não ter salário significa não ter a chave para o futuro. A perda do salário, além disso, interrompe a principal forma de preparação cultural e social para a transição da classe trabalhadora à moradia independente em nossa cultura - a formação do "casal" e a preparação para a família nuclear.

\section{Como as diferenças sociais interferem nesse processo?}

Ter acesso, assim como dar acesso, ao "salário familiar" masculino é ainda uma das bases materiais mais importantes para o flerte, o romance e a formação de casais. Para sair da casa dos pais nos melhores termos e começar a pensar em ter a própria família, a jovem precisa do poder de provisão alargado do salário masculino (ainda hoje 60\% maior do que o feminino). Para que o jovem consiga "dar conta do recado", com todas as despesas adicionais de ter uma residência independente, ele precisa do trabalho doméstico "gratuito" para obter o máximo dos bens de subsistência adquiridos com seu salário. Isso confere todo um escopo afetivo à deferência feminina, à admiração e ao suporte emocional do homem, e, por sua vez, ao cuidado e à proteção patriarcal da mulher pelo homem.

Além de prover os meios para viver de forma independente, qual é o papel do trabalho na vida adulta?

Há também transições culturais e subjetivas muito importantes associadas a estar no domínio mesmo da produção formal. Apesar das dificuldades e dos sacrifícios do trabalho moderno, há, contudo, uma espécie de emancipação em direção a uma vida adulta política genérica associada ao trabalho. Isso é muito mais do que ter direito ao voto a cada cinco anos. Trata-se do envolvimento pessoal na "luta diária contra a natureza" a fim de prover as necessidades e vontades humanas. É claro que o trabalho doméstico e a produção são muito importantes e têm sido subestimados, mas o modo coletivo de produção dominante é o capitalista e, de qualquer forma, está invadindo as funções domésticas e convertendo-as em bens de consumo. Mesmo que você seja o parceiro mais fraco e explorado nessa produção 
capitalista, ainda é parte do drama, das lutas de poder que o integram, do principal modo material por meio do qual construímos a nós e aos nossos futuros. Em parte, essa é uma questão de participar democraticamente do poder do sindicalismo. Mas é também uma questão de tomar parte em algumas das práticas culturais, das criatividades informais e das lutas "secretas" pelo controle no trabalho. Grupos de trabalhadores procuram continuamente produzir seu próprio mundo cultural no trabalho com o objetivo de, ou tendo como efeito, entre outras coisas, humanizar a produção e exercer algum controle sobre o ritmo e a organização do trabalho. A estrutura e a produção diária do trabalho consistem nas batalhas e nas negociações com supervisores que tentam constantemente subjugar essa força, por meio de modernas técnicas "centradas no empregado", procurando colonizar o mundo informal e fazer com que ele funcione de acordo com a ideologia e os propósitos da administração. Também para aqueles que trabalham há conhecimentos práticos e habilidades em saber como as coisas "realmente são", um certo conhecimento experimental dos processos e das capacidades humanas envolvidas em ambos.

\section{O que significa ser adulto hoje?}

Essas relações sociais e experiências reais e contestadas são matéria para uma visão "adulta" e "mundana" do mundo: saber como situar e julgar as pessoas; saber quem tem mais probabilidade de estar contra e a favor de você; saber quando falar e quando permanecer em silêncio; saber "o que há realmente por trás das coisas”. Essas experiências e esforços também permitem sucessivos contatos sociais e todo um modo de intimidade e qualidade de relação social que provê mapas de sentido para o mundo, fornecendo uma maneira de situar-se e um retrato tridimensional humano e administrável da localidade, da cidade ou da metrópole em que você vive.

Atualmente, em que tipo de contexto as transiçôes acontecem no Reino Unido?

No Reino Unido, uma proporção significativa de jovens, em especial da classe trabalhadora e com pouca ou nenhuma qualificação, principalmente aqueles pertencentes a minorias étnicas, tem sofrido uma quebra nas transições sobre as quais falei antes. O desemprego é severo e, mesmo que os jovens estejam constantemente lutando para encontrar caminhos diferentes rumo ao futuro, novas transições ou alternativas não têm sido propostas ou 
oferecidas a eles. Apesar da variedade de programas estatais, habilidades, energias e paixões redundantes não têm encontrado novos objetos nem saídas. Você está ou desempregado ou trabalhando em situação de pobreza. Todas as medidas de bem-estar social para os jovens estão ajustadas para inseri-los ou reinseri-los no trabalho assalariado. Sem um trabalho você não é nada. É quase como se os jovens desempregados estivessem engessados na negatividade de sua própria essência: qual é o sentido de uma "classe trabalhadora” sem trabalho? As agruras de não contar com um salário são dupla e triplamente acrescidas pela negação do acesso ao mundo da construção de si por meio do uso criativo dos bens de consumo adquiridos. Uma medida da dureza das condiçôes deterioradas, especialmente para o segmento mais baixo da classe trabalhadora, é o fato de que o limite extremo do que anteriormente era considerado uma derrota honrosa e qualificável - a inserção voluntária no trabalho manual - hoje seja visto como uma "época de ouro" e que qualquer tipo de trabalho seja ardentemente almejado. Uma vez que se torna condicional aquilo que deveria ser um direito de nascença, os filhos da classe trabalhadora agora aspiram ao seu próprio e necessário status! Escravos do contracheque, comemorem seus grilhôes! Ou a perspectiva deles.

Por que, para muitos jovens, essas transições nunca serão completadas? O que fazer, então, como pesquisadores da cultura?

Nunca antes os pobres foram submersos em tamanha estereotipia negativa, em presunções de passividade e, cada vez mais, em formas diferentes de patologia e disfunção social. Hoje, mais do que nunca, nós devemos propiciar aos grupos subordinados uma energia estética e social independente; eles geralmente são dispostos em categorias de comportamento e cultura delinqüentes, aos quais com tanta freqüência são designadas as piores ajudas. Vamos virar a mesa! Mesmo sob condições fragmentadas e obstruídas de transição, vamos imaginar que as culturas subordinadas possam ser mais abertas, mais plásticas e criativas do que as dominantes, porque elas são menos organizadas internamente pelas exigências, inflexibilidades e tradições necessárias à manutenção da dominação: as auto-ilusões necessárias para o exercício da força. William James argumenta que "a experiência, como sabemos, tem maneiras de transbordar, e fazer com que corrijamos nossas fórmulas atuais”. É no registro etnográfico dos transbordamentos da produção cultural em culturas subordinadas que podem estar as chaves para novas formas e con- 
dições estruturais, registradas não apenas como fatos econômicos brutos, mas como ordens segundo as quais as formas simbólicas interceptam e incorporam os fatos, contribuindo para estabelecer os parâmetros de acordo com os quais os sujeitos modernos são constituídos.

Como o senhor explica os fenômenos das transiçôes "estendidas", do "prolongamento" da juventude ou da "pós-adolescência"?

Parte da cultura pós-consumo mediatizada, especialmente para os jovens, parece ter a ver com marcar etapas de transição apenas por marcá-las, pois não há perspectivas de transições efetivas a destinos finais. Tanto o início como o final da transição se encontram desconectados da realidade material ou contêm apenas referentes puramente simbólicos. Richard Hoggart escreveu nos anos de 1950 sobre um breve intervalo de tempo durante o qual jovens mulheres da classe trabalhadora nas comunidades tradicionais de trabalhadores do pré-guerra gozavam de um rápido período de "vida de borboleta", constituído por saídas com as amigas depois de deixarem a escola e antes de se estabelecerem na rotina sem graça de seus lares maritais. É quase como se esse estágio de "borboleta" tivesse se tornado uma aspiração social permanente. Pode muito bem ser o caso de a diversão associada a esse período extremamente curto de transição para a vida independente, de arranjar um emprego e de estabelecer-se, sempre ter sido mais divertida do que o que vinha depois. Mas, se há incerteza em toda parte, então por que não empregar os esforços e investimentos simbólicos para transformar o supérfluo no sentido da vida? Há um pouco do puer eternis em todas as coisas de nossas vidas consumistas, mesmo quando já somos adultos. Os rituais e a diversão de antes do ingresso em um novo estágio de vida, que outrora eram associados a um curto período, agora se expandiram em novas possibilidades, novos conjuntos de relações horizontais a serem aproveitadas por elas mesmas, e novas e alargadas formas de "viver para o hoje". Isso é um indicador do quanto estamos nos tornando, se você preferir, adolescentes permanentes.

Embora com importantes componentes imaginários, isso também tem efeitos colaterais reais devido ao trabalho envolvido, incluindo a possibilidade de formação de novas identidades, desalojando identidades ulteriores porque elas não se fixam aos destinos esperados.

Na entrevista de 1998, o senhor afirmou não ser mais possivel saber onde estão 
os jovens de hoje. Por quê?? Onde estão os jovens? É possivel identificar novas formas de expressão cultural?

No mundo da cultura de consumo e do mercado virtual, ninguém sabe se você é da classe trabalhadora ou de que parte da cidade você vem, ou qual é sua posição política. Aparentemente você pode abandonar seu passado. Que novas maneiras estão sendo desenvolvidas para incorporar identidades concretas, sexuais, raciais e de classe? Que novas corporificaçôes da sensualidade de um "manualismo" da classe trabalhadora estão se manifestando? Que novas transições são visualizadas através do vidro escurecido da cultura vivida, e a que se destinam? Mas não podemos nomear e reconhecer essas práticas culturais. Elas são ora patologizadas e vistas como "o problema da juventude de hoje”, ora simplesmente obliteradas pela dominância das línguas oficiais, por falarem de cultura como "cultura erudita": as formas simbólicas que são altamente valorizadas, que atraem patrocínio e reconhecimento, e que são mobilizadas para controlar as áreas de subsídio, acesso e influência. A estética oculta "das massas" nunca é percebida, reconhecida, analisada, ensinada. Então não há como desencaixotar, dignificar e compreender, ou mesmo enxergar, a tragicomédia dos efeitos reais que fluem, incompreendidos, quando o puer eternis, a vida de borboleta preternaturalmente expandida de uma "juventude" cada vez mais alargada encontra as estatísticas invencíveis da exploração capitalista e a interferência estatal tanto nos salários de fome como no penoso desemprego de longa duração.

\section{Referências Bibliográficas}

WiLlis, P. (1981), Aprendiendo a trabajar. Cómo los chicos de clase obrera consiguen trabajos de clase obrera. Madri, Akal (1 ed. 1977). (Original inglês: Learning to labour. How working class kids get working class jobs. Aldershot, Gower.) . (1978), Profane culture. Londres, Routledge \& Kegan Paul. . (1987), "Notes on method". In: et al. Culture, media, language: working papers in cultural studies, 1972-79. Londres, Hutchinson/CCCS (1 ed. 1980). et al. (1988), The Youth Review. Aldershot, Gower.

. (1993), "Producción cultural no es lo mismo que reproducción cultural, que a su vez no es lo mismo que reproducción social, que tampoco es lo mismo que reproducción”. In: Velasco, H. M., García, F. J. \& Díaz, A. (eds.). Lecturas de 
antropología para educadores. El ámbito de la antropología de la educación y de la etnografía escolar. Madri, Trotta (1 ed. 1981).

. (1996), Common culture: symbolic work at play in the everyday cultures of the young. Milton Keynes: Open University Press (1 ed. 1990).

. (1998), Cultura viva: una recerca sobre les activitats culturals dels joves. Barcelona, Diputació de Barcelona (1 ed. 1990). (Original inglês: Moving culture: an inquiry into the cultural activities of young people. Londres, Gulbenkian Foundation.)

(2000), The Ethnographic imagination. Cambridge, PolityPress.

Texto recebido e aprovado em 25/10/2005.

Melissa Mattos Pimenta é doutoranda em Sociologia pela FFCH-USP.Email: melissa_mpimenta @yahoo.com.br. 